\title{
The Relationship between Cardiac Output, Cerebral Electrical Activity, Cerebral Fractional Oxygen Extraction and Peripheral Blood Flow in Premature Newborn Infants
}

\author{
SURESH VICTOR, RICHARD E. APPLETON, MARGARET BEIRNE, ANTHONY G. MARSON, AND A. MICHAEL WEINDLING
}

Division of Child Health [S.V., A.M.W.], University of Liverpool, Liverpool Women's Hospital, Liverpool, UK, L8 7SS; Department of Neurology [R.E.A., M.B.], Royal Liverpool Children's Hospital (Alder Hey), Liverpool, UK, L12 2AP; Division of Neurological Science [A.G.M.], University of Liverpool, Clinical Sciences Centre, Liverpool, UK, L9 7LJ

\begin{abstract}
Cardiac output is a determinant of systemic blood flow and its measurement may therefore be a useful indicator of abnormal hemodynamics and tissue oxygen delivery. The purpose of this study was to investigate in very premature newborn infants the relationships between cardiac output (left and right ventricular outputs), systemic blood pressure, peripheral blood flow (PBF) and two indicators of cerebral oxygen delivery (cerebral electrical activity and cerebral fractional oxygen extraction (CFOE)). This was a prospective observational study performed on 40 infants of less than $30 \mathrm{wk}$ gestation. Digital electroencephalograms (EEGs) were recorded for one hour every day during the first four days after birth and subjected to qualitative and quantitative analysis. Left and right ventricular outputs, mean blood pressure (MBP), CFOE, PBF and arterial blood gases were measured at the same time. Within the ranges studied, there was no apparent relationship between left or right ventricular output (RVO), PBF and indicators of cerebral perfusion (cerebral electrical activity and CFOE). The EEG was normal in infants with low left and right ventricular outputs $(<150 \mathrm{~mL} / \mathrm{kg} / \mathrm{min})$ and $\mathrm{MBP}>$ $30 \mathrm{~mm} \mathrm{Hg}$. Infants with low cardiac output and normal MBP seem able to maintain cerebral perfusion, possibly through vasodilatation of the cerebral microvasculature. (Pediatr Res 60: 456-460, 2006)
\end{abstract}

$\mathrm{B}$ lood pressure is routinely monitored in neonatal units. Clinicians rely on its absolute value to guide therapy and the prescription of volume expanders and inotropes. However, systemic blood pressure is the product of systemic vascular resistance and cardiac output and is not a direct indicator of the systemic blood flow. Nevertheless, the clinician's approach is based on the assumption that hypotension causes decreased organ perfusion, including that of the brain, resulting in tissue damage. Furthermore, the relationship between MBP and cerebral blood flow remains unclear $(1,2)$; it is presumed that cerebral blood flow is preserved by autoregulation even in very preterm babies but the limits of autoregulation are uncertain.

Although cardiac output might reasonably be expected to be a major determinant of systemic blood flow (and therefore of tissue oxygen delivery), the relationship is not a simple one.

Received February 1, 2006; accepted May 30, 2006.

Correspondence: Suresh Victor, M.B.B.S., M.R.C.P.C.H., Neonatal Intensive Care Unit, Liverpool Women's Hospital Crown Street, Liverpool, L8 7SS, United Kingdom; e-mail: svictor@liverpool.ac.uk

Funding by Newborn Appeal, Liverpool Women's Hospital, Liverpool, L8 7SS

DOI: $10.1203 / 01 . p d r .0000238379 .67720 .19$
Thus, a study of preterm infants with closed or insignificant patent ductus arteriosus, showed a weak but significant correlation between mean blood pressure (MBP) and left ventricular output (LVO) overall, but LVO was normal for some babies with low MBP, while for others MBP was normal when ventricular output was low (3).

There have been relatively few studies of the relationship between cardiac output and cerebral perfusion in the human preterm infant. A recent study of infants between 24 and 30 wk gestation measured cerebral fractional oxygen extraction (CFOE) as a proxy measure of cerebral oxygen delivery: CFOE is increased when cerebral oxygen delivery is low. There was a weak but significant negative correlation between LVO and cerebral fractional oxygen extraction (4). Infants were particularly vulnerable to poor cerebral oxygenation in the presence of hypocarbia. Both this and other studies found no significant relationship between MBP and CFOE $(4,5)$. However, in these studies there was no recording of cerebral electrical activity, which is affected by cerebral hypoperfusion and consequent cerebral hypoxia because much of the oxygen delivered to the brain goes to maintain transmembrane ion gradients (6).

Although extremely preterm infants are often treated with high doses of pressor agents to maintain blood pressure (in the expectation that this will preserve organ perfusion), the relationship between cardiac output and cerebral electrical activity has not been previously studied in this vulnerable group. The purpose of this study was to determine whether changes in cardiac output were associated with changes in cerebral electrical activity, peripheral blood flow and cerebral fractional oxygen extraction.

\section{METHODS}

This was a prospective observational study performed on 40 very low birth weight infants of less than $30 \mathrm{wk}$ gestation born at Liverpool Women's Hospital. The upper limit of $30 \mathrm{wk}$ gestation was chosen, as well developed sleep-wake cycling is generally not seen below this gestation $(7,8)$. Further-

Abbreviations: CFOE, cerebral fractional oxygen extraction; LVO, left ventricular output; MBP, mean blood pressure; $\mathbf{P a C O}_{2}$, arterial carbon dioxide tension; PBF, peripheral blood flow; RVO, right ventricular output 
more, interburst intervals have been shown not to change with gestation below $30 \mathrm{wk}$ (9) and it is therefore reasonable to consider babies at all gestations below $30 \mathrm{wk}$ to be electroencephalographically similar for the purposes of the study. Measurements were made every day on the first four days after birth. Ethical approval was obtained from the Liverpool Children's Research Ethics Committee and informed parental consent was obtained. Infants who had serious intra-ventricular hemorrhage (defined as any hemorrhage extending beyond the germinal matrix) during the first two days after birth were excluded. All infants had normal blood glucose concentrations at the time of measurements.

Electroencephalography (EEG). Digital EEG and electrocardiography (ECG) recordings were performed for $75 \mathrm{~min}$ on each of the four days of the study using a Micromed 16-channel system (Micromed Electronics Ltd, UK). Six electrodes were placed on the frontopolar (Fp1, Fp2), central (C3, C4) and occipital $(\mathrm{O} 1, \mathrm{O} 2)$ positions bilaterally according to the International 10-20 system (10). A reference electrode was placed at the vertex (Cz). Skin impedance of less than $2 \mathrm{k} \Omega$ was maintained for all recordings. A sampling rate of $256 \mathrm{~Hz}$ was used for digitisation.

The EEG was analyzed qualitatively and quantitatively. RA and MB experienced at reporting neonatal and pediatric EEGs provided the qualitative reports. They were blinded to MBP, ventricular outputs, arterial blood gases and cranial ultrasound scan findings. The EEG was displayed on a computer screen as four bipolar channels (Fp1 - C3, C3 - O1, Fp2 - C4 and C4 - O2). A high pass filter of $0.3 \mathrm{~Hz}$, a low pass filter of $70 \mathrm{~Hz}$, a notch filter of $50 \mathrm{~Hz}$, a base time of $10 \mathrm{~s}$ and a gain of $100 \mu \mathrm{V}$ were used. The EEG traces were reported for discontinuity, amplitude, abnormal transients and synchrony.

Quantitative analysis of the EEG was undertaken by spectral analysis and manual calculation of the interburst interval (9). Gross artefacts (activity with no identifiable EEG activity) were identified by eye and removed manually in 10 -s intervals. The methods used in this quantitative analysis have been described in detail elsewhere (9). The interburst interval was defined as a period between electrical bursts during which activities were lower than $30 \mu \mathrm{V}$ in all leads and calculated manually (11). The $90^{\text {th }}$ centile for interburst interval was then calculated for the first $60 \mathrm{~min}$ of artefact-free recording (9).

The first 60 min of artefact-free EEG was subjected to spectral analysis by Fast Fourier Transformation using the manufacturer's software (Micromed) (9). Six monopolar channels were used for analysis (Fp1, Fp2, C3, C4, O1 and $\mathrm{O} 2)$. The spectrum was subdivided into delta $(0.5-3.5 \mathrm{~Hz})$, theta $(4-7.5 \mathrm{~Hz})$, alpha $(8-12.5 \mathrm{~Hz})$ and beta $(13-30 \mathrm{~Hz})$ bands. The absolute and relative powers of each band were calculated for every 10-s interval. The absolute power of a band was defined as the integral of all the power values over the frequency range and expressed as $\mu \mathrm{V}^{2}$. The relative power of a frequency band was defined as the ratio of the absolute power of that frequency band to the total power of all frequency bands and expressed as a percentage. The median absolute power of each band and each band's power relative to the power of the total EEG signal were calculated. The relative power of the delta band had been previously found to be the most repeatable spectral measurement (coefficient of repeatability $=8 \%$ ) (9). It was therefore decided a priori to use the relative power of delta EEG band only for the analysis.

Cerebral fractional oxygen extraction (CFOE). Measurements were made during an EEG recording. The Hamamatsu NIRO 500 and a pulse oximeter in beat to beat mode (Datex-Ohmeda) were used with partial jugular venous occlusion to measure cerebral venous oxygen saturation $\left(\mathrm{CSvO}_{2}\right)$ $(5,12) . \mathrm{CSvO}_{2}$ was calculated as the mean of five partial jugular venous occlusions over a 5-10 min period (12). Cerebral arterial oxygen saturation $\left(\mathrm{CSaO}_{2}\right)$ was assumed to be equal to peripheral arterial oxygen saturation. CFOE was calculated using the formula: $\mathrm{CFOE}=\mathrm{CSaO}_{2}-\mathrm{CSvO}_{2} / \mathrm{CSaO}_{2}$ $(9,19)$. The mean \pm SD of CFOE in clinically stable infants between 27 and 31 wk gestation is $0.29 \pm 0.06$ (5).

Peripheral blood flow $(\boldsymbol{P B F})$. PBF was measured using a method that has been described elsewhere in detail (13). Measurements were made during an EEG recording. The Hamamatsu NIRO 500 and a pulse oximeter in beat-tobeat mode (Datex-Ohmeda) were used to measure total tissue hemoglobin concentration $(\triangle \mathrm{HbT})$ in the forearm. Hemoglobin flow was then calculated by the slope of a line through the $\Delta \mathrm{HbT}$ values during the first two seconds of occlusion using a least squares method (13). PBF (mL/100 mL/min) was calculated by dividing hemoglobin flow by venous hemoglobin concentration. The normal range (minimum-maximum) of PBF in infants between 28 and $32 \mathrm{wk}$ gestation is $6.1-13.4 \mathrm{~mL} / 100 \mathrm{~mL} / \mathrm{min}$ (13).

Echocardiography. Cardiac output was measured using echocardiography. The Sonotron (Vingmed CFM 725) echocardiography machine was used. The images obtained during the examination were stored in an integrated digital archiving system (Echopac, version 5.3; GE Ultrasound) and analyzed using the manufacturer's software. The technique used to determine left and right ventricular output (RVO) has been described in detail elsewhere (14). Ventricular output of $150 \mathrm{~mL} / \mathrm{kg} / \mathrm{min}$ was taken as the lower limit of normal (15).
Presence of patent foramen ovale and ductus arteriosus was noted at the time of measurement.

To determine the LVO, the left ventricular outflow tract was imaged from the suprasternal view. The pulse Doppler range gate was placed distal to the aortic valve and aligned along the long axis of the aorta. The flow velocity time signal was recorded and the velocity time integral was averaged from five pulsed Doppler complexes with laminar flow. The heart rate was measured from peak to peak intervals of the Doppler velocity time signals. The internal diameter of the ascending aorta was measured at the end of systole using M-mode from a parasternal long axis view. Measurements from five cardiac cycles were averaged. The incorporated Echopac software package was used to calculate the $\mathrm{LVO}$ (in $\mathrm{mL} / \mathrm{kg} / \mathrm{min}$ ) using the formula: $\mathrm{LVO}=$ [Velocity time integral $\times\left(3.1416 \times\left[\right.\right.$ outflow diameter $\left.\left.{ }^{2} / 4\right]\right) \times$ heart rate] $/$ body weight.

The same approach was used to determine the RVO. Two-dimensional (2-D) imaging was used to determine the diameter of the pulmonary artery as measured between the hinge points of the pulmonary valve seen from the parasternal long axis view by tilting the probe away from the left shoulder. Pulsed-wave Doppler was used in the same position to determine the pulmonary artery flow velocity integral.

Clinical data. Blood pressure was monitored using a Nova-dome pressure transducer (Micromed Ltd, UK) attached to an indwelling arterial catheter. MBP measurements were recorded every four minutes during the EEG recording. The mean of these measurements during the EEG recording was used for analysis. Arterial blood gas measurement from the indwelling arterial line was performed midway through the EEG recording. Clinical Risk Index for Babies (CRIB) score was calculated (16).

Clinical management. The attending physician, who was not a member of the research group, determined the management of hypotension. It was the policy of the neonatal unit at this hospital to keep the MBP above the $10^{\text {th }}$ percentile for the infant's birth weight (17). This was achieved by volume expansion using blood transfusion or normal saline and/or inotropes such as dopamine, dobutamine or hydrocortisone either singly or in combination. Also in accordance with the policy of the neonatal unit at this hospital, all infants with birth weight less than $1250 \mathrm{~g}$ were treated with indomethacin for three days after delivery (18).

Follow-up measurements. Cranial ultrasound scans were performed on all infants on each day for the first four days after birth and repeated at regular fortnightly intervals before discharge.

Statistical analysis. The data from each of the four days were analyzed separately. Since the purpose of this study was to investigate the cerebrovascular effects of low ventricular output, the EEG and CFOE measurements made at the lowest ventricular output during the first four days after birth were chosen for analysis. The relationships with left and right ventricular output measurements were analyzed separately.

The relationships between the ventricular outputs and CFOE, peripheral blood flow and EEG were considered separately using Pearson's correlation.

Step-wise linear regression was performed. The relative power of delta frequency band, $90^{\text {th }}$ percentile of interburst interval and CFOE were used as the outcome variables and arterial carbon dioxide tension $\left(\mathrm{PaCO}_{2}\right)$, left and right ventricular outputs, mean blood pressure and gestational age were entered as predictor variables.

\section{RESULTS}

The demographic details of the 40 infants are described in Table 1. The data from each of the four days are shown in Table 2. There was a progressive rise in LVO, RVO and MBP over the first four days after birth. The $\mathrm{PaCO}_{2}$ was unchanged, but there was an increase in the relative power of the delta band in the EEG between days one and four and the interburst

Table 1. Demographic details of the cohort $(n=40)$

\begin{tabular}{lc}
\hline \multicolumn{1}{c}{ Characteristics } & Median (Range) \\
\hline Gestational age (weeks) & $27(23-30)$ \\
Birth weight (grams) & $947(470-1498)$ \\
Males (n) & 19 \\
Cord base deficit & $2.0(9.6$ to -1.3$)$ \\
Apgar at 5 minutes & $8(4-10)$ \\
CRIB score & $3(0-17)$ \\
\hline
\end{tabular}

CRIB, Clinical risk index for babies. 
Table 2. The median (range) [n] of measurements when EEG recordings were made during the first four days after birth

\begin{tabular}{|c|c|c|c|c|}
\hline Measurement & Day 1 & Day 2 & Day 3 & Day 4 \\
\hline $\mathrm{LVO}(\mathrm{mL} / \mathrm{kg} / \mathrm{min})$ & $191(58-417)[36]$ & $268(92-680)[40]$ & $271(134-697)[38]$ & $288(151-776)$ [27] \\
\hline $\mathrm{RVO}(\mathrm{mL} / \mathrm{kg} / \mathrm{min})$ & $200(94-437)[36]$ & $303(81-678)[40]$ & 318 (142-687) [37] & $370(178-723)[25]$ \\
\hline MBP (mm Hg) & $33(16-52)$ [37] & $38(20-51)[38]$ & $41(27-56)[26]$ & $42(23-57)[17]$ \\
\hline RP of delta $(\%)$ & $68(20-80)[37]$ & $73(60-87)[40]$ & $77(66-88)[39]$ & $78(58-89)[31]$ \\
\hline $\mathrm{P}_{90} \mathrm{IBI}(\mathrm{s})$ & $15(7-53)[37]$ & $12(4-31)[40]$ & $9(5-16)[39]$ & $9(3-16)[31]$ \\
\hline CFOE & $0.35(0.22-0.64)[27]$ & $0.29(0.14-0.62)[28]$ & $0.30(0.11-0.73)[23]$ & $0.3(0.2-0.6)[17]$ \\
\hline
\end{tabular}

RP, relative power; $\mathrm{P}_{90} \mathrm{IBI}, 90^{\text {th }}$ percentile for interburst interval.

interval became shorter. CFOE decreased between days one and two and PBF increased.

All infants had patent foramina ovale at the time of recording. Twelve infants had patent ductus arteriosus. In ten of these infants, ductal diameters were less than $1.5 \mathrm{~mm}$. The conditions of infants at the time of recording the lowest left and right ventricular outputs during the first four days after birth are shown in Table 3. The median $\mathrm{PaCO}_{2}$ in 10 infants with low LVO was $41 \mathrm{~mm} \mathrm{Hg}$ (range 26-57). The median $\mathrm{PaCO}_{2}$ in 8 infants who had a low RVO was $39 \mathrm{~mm} \mathrm{Hg}$ (range 32-57). Only four infants were reported to have an abnormal EEG by qualitative methods.

The relationships between MBP, right and left ventricular outputs and the EEG signal are shown in Figs. 1 and 2. The four qualitatively abnormal EEG signals were seen at low levels of MBP, but not cardiac output. These EEGs were low amplitude traces with prolonged interburst interval. Case A (Figs. 1 and 2) with a MBP of $16-\mathrm{mm} \mathrm{Hg}$ had significant patent ductus arteriosus (diameter $>3 \mathrm{~mm}$ ). This infant was given dopamine, dobutamine and hydrocortisone because of hypotension.

There was no relationship between cardiac output from either left or right ventricle and quantitative EEG measurements or CFOE or peripheral blood flow (Tables 4 and 5). There was a similar lack of relationship between cardiac output and CFOE in infants who were treated and those who were not treated with inotropes.

The results obtained using Pearson's correlations were confirmed by step-wise multiple linear regression. Ventricular outputs and gestational age did not influence the relationships.

Table 3. Condition of infants at the time of recording left and right ventricular outputs during first 48 hours after birth [ $n=40]$

\begin{tabular}{lcc}
\hline & LVO & RVO \\
\hline Age at recording (hours) & $12.5(5-43)$ & $13(5-46)$ \\
$\mathrm{MBP}(\mathrm{mm} \mathrm{Hg})$ & $33(16-50)$ & $33(16-47)$ \\
$\mathrm{LVO}(\mathrm{mL} / \mathrm{kg} / \mathrm{min})$ & $190(58-417)$ & - \\
$\mathrm{RVO}(\mathrm{mL} / \mathrm{kg} / \mathrm{min})$ & - & $202(81-478)$ \\
$\mathrm{PBF}(\mathrm{mL} / 100 \mathrm{~mL} / \mathrm{min})$ & $4.43(2.01-9.69)$ & $5.75(2.01-12.8)$ \\
$\mathrm{CFOE}$ & $0.33(0.22-0.43)$ & $0.32(0.22-0.42)$ \\
$\mathrm{pH}$ & $7.33(7.20-7.53)$ & $7.33(7.20-7.53)$ \\
$\mathrm{PaCO}_{2}(\mathrm{~mm} \mathrm{Hg})$ & $41(26-60)$ & $41(24-60)$ \\
$\mathrm{PaO}_{2}(\mathrm{~mm} \mathrm{Hg})$ & $65(38-156)$ & $66(38-134)$ \\
$\mathrm{Use}_{\text {of inotropes }}(\mathrm{n})$ & 18 & 17 \\
Ventilated (n) & 38 & 39 \\
\hline
\end{tabular}

All results are in median (range).

$\mathrm{PaO}_{2}$, arterial oxygen tension.

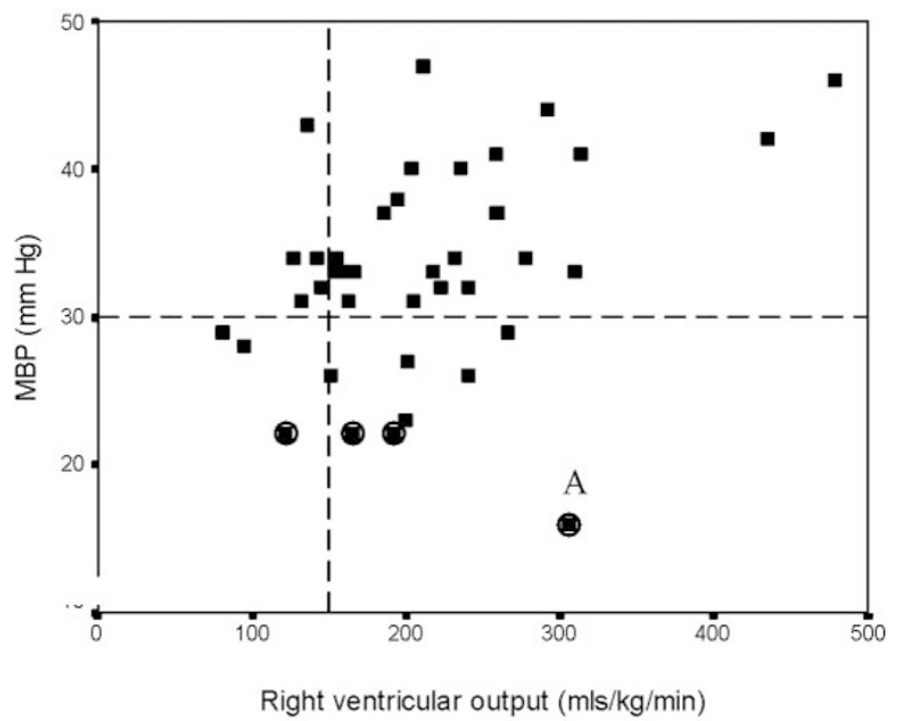

Figure 1. The relationships between RVO, MBP and EEG $[n=40, \mathrm{r}=$ 0.39*]. (A) indicates the patient with MBP of $16-\mathrm{mm} \mathrm{Hg}$ and significant patent ductus arteriosus (diameter $>3 \mathrm{~mm}$ ). Infants with qualitatively abnormal EEG records have been circled $(n=4)$. $* p=0.01$

Case A is an outlier in both Figs. 1 and 2. The results did not change significantly after the exclusion of this patient.

None of the 40 infants developed persistent echogenicity or cystic periventricular leukomalacia on the cranial ultrasound scans.

Four infants had abnormal EEGs. One of these had gross ventricular dilatation on later cranial ultrasound scans. The other three infants with abnormal EEG records had normal follow-up cranial ultrasound scans.

Of the 36 infants with normal EEG, 33 had cranial ultrasound scans, which remained normal or showed resolving sub-ependymal or intraventricular hemorrhages. Two other infants developed mild ventricular dilatation following intraventricular hemorrhages. The rate of increase in head circumference measurements was along the percentiles for the normal population for all except one infant, who developed hydrocephalus requiring shunt surgery.

\section{DISCUSSION}

This study found no relationship between cardiac output and cerebral electrical activity, peripheral blood flow or cerebral fractional oxygen extraction during the days after birth. As reported by others, there was a progressive increase in 


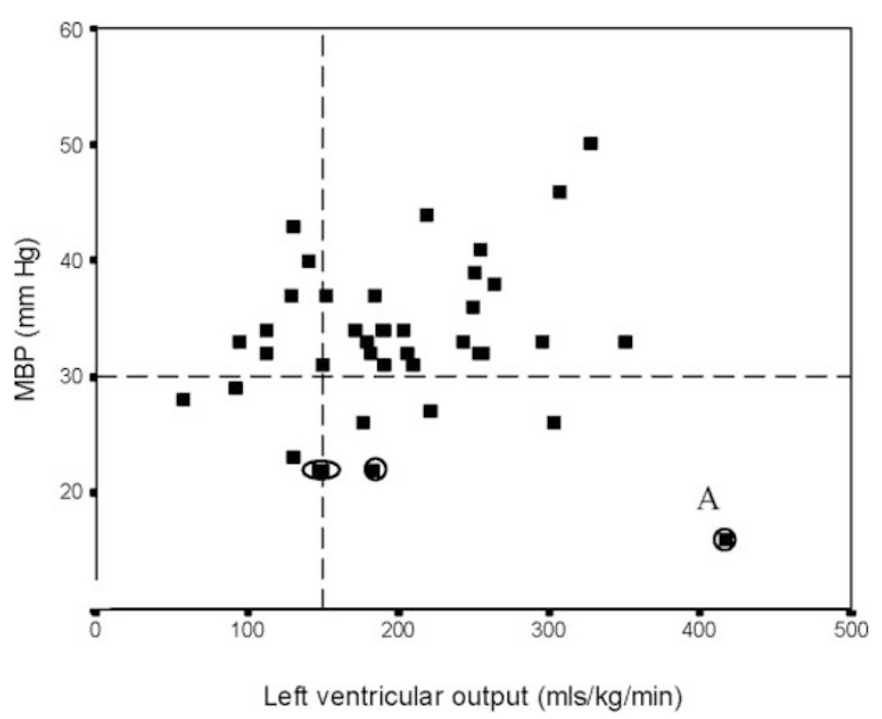

Figure 2. The relationships between LVO, MBP and EEG $[n=40, \mathrm{r}=$ $0.1^{*}$. (A) indicates the patient with MBP of $16-\mathrm{mm} \mathrm{Hg}$ and significant patent ductus arteriosus (diameter $>3 \mathrm{~mm}$ ). Infants with qualitatively abnormal EEG records have been circled $(n=4) .{ }^{*} p=0.54$

Table 4. Results of Pearson's correlation between variables when left ventricular output $(L V O)$ was measured [ $n=40]$

\begin{tabular}{lccccc}
\hline & & \multicolumn{4}{c}{ Predictor variable } \\
\cline { 2 - 6 } Outcome variable & & LVO & MBP & $\mathrm{PaCO}_{2}$ & Gestation \\
\hline Peripheral blood flow & $\mathrm{r}$ & 0.198 & 0.189 & 0.165 & 0.086 \\
$(\mathrm{n}=18)$ & $\mathrm{p}$ & 0.430 & 0.454 & 0.513 & 0.736 \\
Relative power of & $\mathrm{r}$ & -0.277 & 0.495 & -0.328 & 0.80 \\
delta band & $\mathrm{p}$ & 0.083 & $0.001 *$ & $0.039^{*}$ & 0.622 \\
$\mathrm{P}_{90}$ interburst interval & $\mathrm{r}$ & 0.12 & -0.466 & 0.361 & -0.128 \\
& $\mathrm{p}$ & 0.462 & $0.002^{*}$ & $0.022^{*}$ & 0.432 \\
CFOE (n $=26)$ & $\mathrm{r}$ & -0.020 & -0.112 & -0.464 & 0.064 \\
& $\mathrm{p}$ & 0.922 & 0.587 & $0.017^{*}$ & 0.755 \\
\hline
\end{tabular}

* Significant at $p<0.05$

$\mathrm{p}$, level of significance; $r$, Pearson's correlation coefficient. $\mathrm{P}_{90}, 90^{\text {th }}$ percentile.

LVO and RVO and, blood pressure after birth $(3,17)$. The CFOE decreased, presumably as cerebral perfusion improved. There was also a significant relationship between $\mathrm{PaCO}_{2}$ and MBP and the EEG signal.

The EEG pattern of infants between 26 and 30 wk gestation has been characterized (19). It is markedly discontinuous and consists of long periods of electrical quiescence ("interburst intervals") which are interspersed with bursts of high voltage mixed frequency activity (19). With increasing gestation, the interburst intervals become shorter and the record becomes more continuous $(20,21)$. Abnormal background EEG activity characterized by prolonged interburst intervals has been linked to adverse neurologic outcome $(22,23)$. The negative correlation between $\mathrm{PaCO}_{2}$ and the relative power of the delta band suggested slowing of the EEG with hypocarbia (24). Suppression or prolonged discontinuity of the EEG occurred at MBP levels below $23 \mathrm{~mm} \mathrm{Hg}$ (25). The EEG abnormalities in relation to $\mathrm{PaCO}_{2}$ and $\mathrm{MBP}$ observed during this study have been described in detail elsewhere $(24,25)$. The remainder of this discussion concentrates on the lack of any demonstrable relationship between cardiac output, CFOE and EEG and PBF.

During the newborn period, systemic perfusion is not entirely determined by cardiac output because of the presence of shunts (26). Thus, the LVO is the sum of systemic blood flow and any left to right shunt through the patent ductus arteriosus or at atrial level (26). Similarly, the RVO is the sum of systemic venous return and any left to right shunts (26). This absence of an association between systemic blood flow and left and right ventricular outputs is a possible explanation for the apparent lack of any relationship between cardiac output and the EEG, used here as a marker of cerebral perfusion. It is also a reason for suggesting that superior vena caval flow, which is less influenced by shunts, may be a better reflection of cerebral perfusion (27).

It has been suggested that blood pressure may not fall until the natural compensatory mechanisms finally fail, and that a serious decline in cardiac output and tissue oxygen delivery may therefore be detected earlier by measuring cardiac output (14). This did not seem to be the case in this study where all infants with low cardiac output $(<150 \mathrm{~mL} / \mathrm{kg} / \mathrm{min})$ and MBP $>30 \mathrm{~mm} \mathrm{Hg}$ also had a normal EEG. One baby with a very low LVO $(58 \mathrm{~mL} / \mathrm{kg} / \mathrm{min})$ and MBP of $28 \mathrm{~mm} \mathrm{Hg}$ also maintained normal cerebral electrical activity and normal CFOE. These observations suggest that cerebral electrical activity (and therefore cerebral oxygen delivery) may be maintained within normal limits in infants with low cardiac output and normal blood pressure.

The absence of a relationship between the ventricular outputs and the EEG noted in the present study is consistent with the findings of others. In a randomized control trial of 36 preterm infants, dopamine and volume expansion increased LVO but had no effect on global cerebral blood flow (28). When eight preterm infants with respiratory distress syndrome were treated by high frequency ventilation, low LVO was not associated with decreased anterior cerebral artery blood flow (29). However another study reported a relationship between LVO and mean anterior cerebral artery blood flow velocity (30).

Contrary to our expectations, there was no relationship between the ventricular outputs and CFOE. In a previous study, we reported a weak but significant correlation between LVO and CFOE ( $\mathrm{r}=-0.44, p=0.02)$ on the first day after birth in 30 infants between 24 and 28 wk gestation (4). However, this correlation and increase in CFOE was due to a considerable degree to the inclusion of seven infants who were hypocarbic at the same time as having a low LVO. Furthermore, in that study, 11 infants with low LVO and normal $\mathrm{PaCO}_{2}$ did not have high levels of CFOE. In this present study, only one of the infants with low ventricular output was hypocarbic.

In conclusion, left and right ventricular outputs did not appear to be important determinants of cerebral electrical activity or CFOE in the ranges studied. Low ventricular output in the presence of normal MBP was associated with normal cerebral electrical activity and CFOE, suggesting uncompromised cerebral oxygen delivery. 
Table 5. Results of univariate analysis (Pearson's correlation) between variables when right ventricular output (RVO) was measured $[n=40]$

\begin{tabular}{lrrrrr}
\hline & \multicolumn{5}{c}{ Predictor variables } \\
\cline { 2 - 6 } Outcome variable & & \multicolumn{1}{c}{$\mathrm{RVO}$} & $\mathrm{MBP}$ & $\mathrm{PaCO}_{2}$ & Gestation \\
\hline Peripheral blood flow & $\mathrm{r}$ & 0.323 & 0.391 & 0.126 & 0.134 \\
$(\mathrm{n}=18)$ & $\mathrm{p}$ & 0.191 & 0.109 & 0.619 & 0.595 \\
Relative power of & $\mathrm{r}$ & 0.105 & 0.580 & -0.351 & 0.052 \\
delta band & $\mathrm{p}$ & 0.520 & $0.000^{*}$ & $0.026^{*}$ & 0.751 \\
$\mathrm{P}_{90}$ interburst interval & $\mathrm{r}$ & -0.212 & -0.567 & 0.399 & -0.165 \\
& $\mathrm{p}$ & 0.190 & $0.000^{*}$ & $0.011^{*}$ & 0.309 \\
CFOE (n=26) & $\mathrm{r}$ & -0.241 & -0.367 & -0.476 & 0.056 \\
& $\mathrm{p}$ & 0.235 & 0.066 & $0.014^{*}$ & 0.786 \\
\hline
\end{tabular}

* Significant at $p<0.05$.

$r$, Pearson's correlation coefficient; $\mathrm{p}$, level of significance; $\mathrm{P}_{90}, 90^{\text {th }}$ percentile.

There are two possible inferences to be drawn from these observations. The first relates to the control of the cerebral vasculature in these very immature individuals. It appears that even when cardiac output is low and systemic blood pressure is normal, cerebral and peripheral perfusion is maintained. This may be because the cerebral microcirculation even of these very immature infants is vasoactive and vasodilatation may occur to preserve cerebral perfusion (31). The second is of considerable importance to clinicians. The possible side effects and complications of interventions aimed at increasing cardiac output and cerebral oxygen delivery in the presence of moderate hypotension may be inappropriate.

\section{REFERENCES}

1. Lou HC, Lassen NA, Friis-Hansen B 1979 Impaired autoregulation of cerebral blood flow in the distressed newborn infant. J Pediatr 94:118-121

2. Tyszczuk L, Meek J, Elwell C, Wyatt JS 1998 Cerebral blood flow is independent of mean arterial blood pressure in preterm infants undergoing intensive care. Pediatrics 102:337-341

3. Kluckow M, Evans N 1996 Relationship between blood pressure and cardiac output in preterm infants requiring mechanical ventilation. J Pediatr 129:506-512

4. Kissack CM, Garr R, Wardle SP, Weindling AM 2004 Cerebral fractional oxygen extraction in very low birth weight infants is high when there is low left ventricular output and hypocarbia but is unaffected by hypotension. Pediatr Res 55:400-405

5. Wardle SP, Yoxall CW, Weindling AM 2000 Determinants of cerebral fractional oxygen extraction using near infrared spectroscopy in preterm neonates. J Cereb Blood Flow Metab 20:272-279

6. Ichord RN, Kirsch JR, Koehler RC, Traystman RJ 1999 Cerebral anoxia: experimental view. In: Niedermeyer E, Lopes da Silva FH (eds) Electroencephalography: basic principles, clinical applications, and related fields. Williams \& Wilkins, Baltimore, pp 432-444

7. Wakayama K, Ogawa T, Goto K, Sonoda H 1993 Development of ultradian rhythm of EEG activities in premature babies. Early Hum Dev 32:11-30

8. Scher MS, Johnson MW, Holditch-Davis D, Scher MS, Johnson MW, HolditchDavis D 2005 Cyclicity of neonatal sleep behaviors at 25 to 30 weeks' postconceptional age. Pediatr Res 57:879-882
9. Victor S, Appleton RE, Beirne M, Marson AG, Weindling AM 2005 Spectral analysis of electroencephalography in premature newborn infants: normal ranges. Pediatr Res 57:336-341

10. Jasper HH 1958 The Ten - Twenty Electrode System of the International Federation. Electroencephalogr Clin Neurophysiol 10:371-375

11. Biagioni E, Bartalena L, Biver P, Pieri R, Cioni G 1996 Electroencephalographic dysmaturity in preterm infants: a prognostic tool in the early postnatal period. Neuropediatrics 27:311-316

12. Yoxall CW, Weindling AM, Dawani NH, Peart I 1995 Measurement of cerebral venous oxyhemoglobin saturation in children by near-infrared spectroscopy and partial jugular venous occlusion. Pediatr Res 38:319-323

13. Wardle SP, Yoxall CW, Crawley E, Weindling AM 1998 Peripheral oxygenation and anemia in preterm babies. Pediatr Res 44:125-131

14. Alverson DC 2000 Cardiac Output. In: Skinner JR, Alverson DC, Hunter S (eds) Echocardiography for the neonatologist. Churchill Livingstone, London, pp 121-132

15. Alverson DC, Eldridge MW, Johnson JD, Aldrich M, Angelus P, Berman WJr. 1984 Noninvasive measurement of cardiac output in healthy preterm and term newborn infants. Am J Perinatol 1:148-151.

16. The International Neonatal Network 1993 The CRIB (clinical risk index for babies) score: a tool for assessing initial neonatal risk and comparing performance of neonatal intensive care units. Lancet 342:193-198

17. Cunningham S, Symon AG, Elton RA, Zhu C, McIntosh N 1999 Intra-arterial blood pressure reference ranges, death and morbidity in very low birthweight infants during the first seven days of life. Early Hum Dev 56:151-165

18. Fowlie PW, Davis PG 2002 Prophylactic intravenous indomethacin for preventing mortality and morbidity in preterm infants. The Cochrane Database of Systematic Reviews, Issue 3, CD000174. DOI: 10.1002/14651858.CD000174

19. Scher MS 1999 Electroencephalography of the newborn: normal and abnormal features. In: Niedermeyer E, Lopes da Silva FH (eds) Electroencephalography: basic principles, clinical applications, and related fields. Williams and Wilkins, Baltimore, pp 896-946

20. Eyre JA, Nanei S, Wilkinson AR 1988 Quantification of changes in normal neonatal EEGs with gestation from continuous five-day recordings. Dev Med Child Neurol 30:599-607

21. Hayakawa M, Okumura A, Hayakawa F, Watanabe K, Ohshiro M, Kato Y, Takahashi R, Tauchi N 2001 Background electroencephalographic (EEG) activities of very preterm infants born at less than 27 weeks gestation: a study on the degree of continuity. Arch Dis Child Fetal Neonatal Ed 84:F163-F167

22. Biagioni E, Boldrini A, Bottone U, Pieri R, Cioni G 1996 Prognostic value of abnormal EEG transients in preterm and full-term neonates. Electroencephalogr Clin Neurophysiol 99:1-9

23. Marret S, Parain D, Menard JF, Blanc T, Devaux AM, Ensel P, Fessard C, Samson-Dollfus D 1997 Prognostic value of neonatal electroencephalography in premature newborns less than 33 weeks of gestational age. Electroencephalogr Clin Neurophysiol 102:178-185

24. Victor S, Appleton RE, Beirne M, Marson AG, Weindling AM 2005 Effect of carbon dioxide on background cerebral electrical activity and fractional oxygen extraction in very low birth weight infants just after birth. Pediatr Res 58:579-585

25. Victor S, Weindling AM, Appleton RE, Beirne M, Marson AG 2006 Relationship between blood pressure, electroencephalograms, cerebral fractional oxygen extraction and peripheral blood flow in very low birth weight newborn infants. Pediatr Res 59:314-319

26. Evans N, Kluckow M 1996 Early determinants of right and left ventricular output in ventilated preterm infants. Arch Dis Child Fetal Neonatal Ed 74:F88-F94

27. Kluckow M, Evans N 2000 Superior vena cava flow in newborn infants: a nove marker of systemic blood flow. Arch Dis Child Fetal Neonatal Ed 82:F182-F187

28. Lundstrom K, Pryds O, Greisen G 2000 The haemodynamic effects of dopamine and volume expansion in sick preterm infants. Early Hum Dev 57:157-163

29. Laubscher B, van Melle G, Fawer CL, Sekarski N, Calame A 1996 Haemodynamic changes during high frequency oscillation for respiratory distress syndrome. Arch Dis Child Fetal Neonatal Ed 74:F172-F176

30. van Bel F, Walther FJ 1990 Myocardial dysfunction and cerebral blood flow velocity following birth asphyxia. Acta Paediatr Scand 79:756-762

31. Jensen A, Garnier Y, Berger R, Jensen A, Garnier Y, Berger R 1999 Dynamics of fetal circulatory responses to hypoxia and asphyxia. Eur J Obstet Gynecol Reprod Biol 84:155-172 